\title{
Effect of 'Loop Diuretics' on the Salt Secretion in Shark Rectal Gland***
}

\author{
R. Kinne and E. Kinne-Saffran*** \\ Max-Planck-Institut für Biophysik, Heinrich-Hoffmann-Str. 7, D-6000 Frankfurt am Main, Federal Republic of Germany
}

\begin{abstract}
Rectal glands of the shark Scyliorhinus canicula were perfused in situ and the rate of sodium chloride secretion was determined in the absence and presence of various diuretics known to act on the thick ascending limb of Henle's loop in mammalian kidneys. The most potent inhibitor of salt secretion was bumetanide $\left(56^{\mathrm{m}} / \mathrm{s}\right.$ inhibition at $10^{-5} \mathrm{M}$ and complete inhibition at $10^{-4} \mathrm{M}$ ), followed by piretanide, furosemide and Bay g 2821 . In addition chloride transport was dependent on the presence of sodium in the perfusate and was inhibited upto $85 \%$ by $10^{-4} \mathrm{M}$ ouabain. The results obtained on sodium chloride secretion in the shark rectal gland are very similar to the observations made on sodium chloride absorption in the thick ascending limb of Henle's loop in rnammalian kidney. These data therefore support the assumption that the basic elements involved in salt transport of the shark rectal gland and mammalian renal thick ascending limb of Henle's loop might be similar.
\end{abstract}

\section{INTRODUCTION}

The rectal gland of sharks as well as the thick ascending limb of the loop of Henle in the mammalian kidney plays an important role in salt homeostasis, the former by excreting sodium chloride from the blood of the fish into the intestinal canal, the latter by reabsorbing sodium chloride from the tubular fluid into the interstitial fluid. The transport processes of both epithelia - although occuring in opposite direction have many similarities. They proceed against a concentration difference, they are ouabain-sensitive; and chloride is the primary ion which is actively transported. (Burg and Green, 1973; Rocha and Kokko, 1973; Burg, 1976; Silva et al., 1977) Therefore it was suggested that similar biochemical mechanisms might be involved in these transport processes (Silva et al., 1977). In order to find further common properties of the two tissues, the effect of various diuretics - known to act on the ascending limb of the loop of Henle ('loop diuretics') - was investigated on the salt secretion by the rectal gland of the shark Scyliorhinus canicula. It

- Supported by grant FA $48 / 21 \mathrm{z}$ of the Deutsche Forschungsgemeinschaft.

- The experiments were performed in autumn 1978 at the Meeresstation Helgoland of the Biologische Anstalt Helgoland.

-.. Address effective January 1980: Department of Physiology, Albert Einstein College of Medicine of Yeshiva University, 1300 Morris Park Avenue, Bronx, N. Y 10461, USA. was found that all loop diuretics inhibit active sodium chloride transport in the rectal gland perfused in situ in a dose dependent manner with a potency sequence similar to the one observed in mammalian kidneys.

\section{MATERIALS AND METHODS}

Scyliorhinus canicula, of either sex, weighing $0.8-1.2 \mathrm{~kg}$, were used for the experiments. The sharks were kept in tanks with running seawater and fed fresh fish regularly. After segmental transsection of the spinal cord the abdomen was opened by a lower abdominal incision, the artery (a. rectalis) was immediately cannulated with a small polyethylene catheter and the perfusion of the gland was started as soon as the cannula had been tied in place. Then the rectal gland vein and duct were also cannulated with small polyethylene catheters and after appropriate fixation of the gland by needles the perfusion was continued in situ. The gland was perfused from a reservoir gased at room temperature with water-saturated, compressed air by gravity flow at a pressure of approximately $38 \mathrm{~mm} \mathrm{Hg}$ and a flow rate of $1-2 \mathrm{ml} \mathrm{min}^{-1}$. The perfusion solution contained (in millimoles $1^{-1}$ ) $\mathrm{Na}, 280 ; \mathrm{K}, 5 ; \mathrm{Cl}, 288 ; \mathrm{Ca}$, 2.5; $\mathrm{Mg}, 1.5$; phosphate, 1 ; sulfate, 0.5 ; urea, 350; theophylline, 0.25; dibutyryl-cAMP, 0.05; D-glucose, $5 \mathrm{mM}_{i}$ (pH 7.0 when gased with air).

The rectal gland secretion was collected at timed intervals $(10-15 \mathrm{~min})$ in $50 \mu \mathrm{l}$ disposable glass pipet- 
tes. Sodium and chloride in the perfusion fluid, the vein effluent and the gland secretion were measured by ionselective electrodes (Orion 96-17 and Orion 96-11). After perfusion the rectal gland was removed, freed from adhering connective tissue and weighed. The average weight of 8 glands was $0.164 \pm 0.04 \mathrm{~g}$ Ouabain (Merck AG, Darmstadt, FRG), furosemide (Lasix ${ }^{(3)}$ Hoechst Pharmaceuticals), piretanide (Hoechst Pharmaceuticals), bumetanide (Dr. Karl Thomae GmbH, Biberach an der Riss) and Bay g 2821 (Bayer Pharmaceuticals, Leverkusen) were dissolved in perfusate solution by stirring overnight. Dibutyrylcyclic AMP, disodium salt (Boehringer, Mannheim) and theophylline (Merck AG, Darmstadt) were added to the perfusate, just before the perfusion started.

Mean values with standard deviation are given throughout the paper where appropriate.

\section{RESULTS}

\section{General Characteristics of Salt Secretion}

In 15 control perfusion periods - before the addition of diuretics and 1-3 h after start of the perfusion - the volume secreted by the gland was $1.34 \pm$ $0.35 \mathrm{ml} \mathrm{h}^{-1} \mathrm{~g}^{-1}$ wet weight and the sodium concentration was $483 \pm 65$ mval. In five experiments the chloride concentration in the secreted fluid could also be determined, at a sodium concentration of $448 \pm$ 40 Inval the chloride concentration was $421 \pm 68$ mval. The glands could be perfused for $4 \mathrm{~h}$ without an appreciable loss of the ability to secrete and to concentrate. Replacement of sodium in the perfusate by

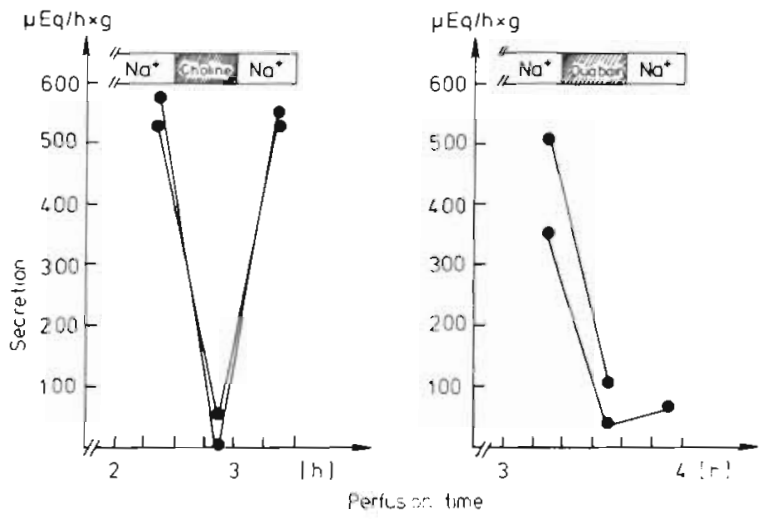

Fig. 1. Scyliorhinus canicula. Effect of sodium removal and ouabain on salt secretion by the rectal gland. In the left panel, sodium in the perfusate was replaced by choline and the secretion of chloride was determined. In the right panel, ouabain $\left(10^{-4} \mathrm{M}\right)$ was added to the perfusate and the secretion of sodium was measured. Bars: solution used during perfusion period. Individual experiments are represented by points connected with each other choline decreased the volume secreted to $\sim 6 \%$ of the control ( $11.5 \%$ and $0 \%, \mathrm{n}=2)$ and in the presence of $10^{-4} \mathrm{M}$ ouabain the secretion was only $15 \%(20 \%$ and $10 \%, n=2$ ) of the control (Fig. 1). The secretion was also dependent on the presence of theophylline and dibutyryl-cAMP in the perfusion fluid, in their absence the secretion dropped to $10 \%$ of the control $(\mathrm{n}=1)$ ). Addition of theophylline and dibutyryl-cAMP to the perfusate reestablished the normal function of the gland in $15 \mathrm{~min}$, so did the readdition of sodium to the sodium-free perfusion medium. The action of ouabain was only slightly $(\sim 20 \%)$ reversible in this time period.

\section{Action of 'Loop Diuretics' on the Secretion}

The results of the experiments performed with Bay $g$ 2821, bumetanide, furosemide and piretanide are compiled in Figure 2.

At a concentration of $10^{-4} \mathrm{M}$ and $10^{-5} \mathrm{M}$ all diuretics tested decrease the salt secretion of the gland (Fig. 2),

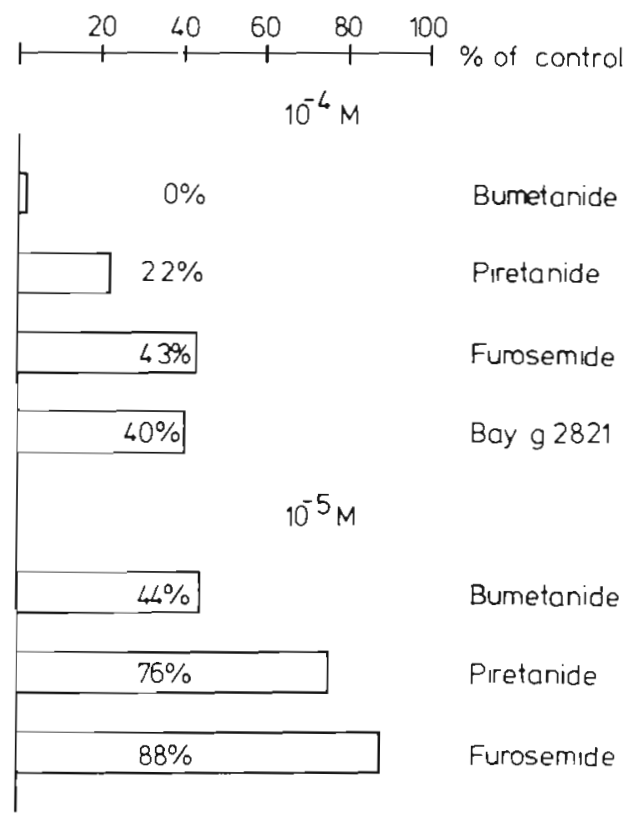

Fig. 2. Scyliorhinus canicula. Inhibition of salt secretion in rectal gland by 'loop diuretics'. All values expressed as percent of secretion observed in the preceding control perfusion period. Data represent average of two perfusion periods, the deviation of each individual result from the mean value was usually less than $10 \%$

mainly by lowering the volume of the secreted fluid. Thereby the sodium concentration of the secreted fluid (and thus probably the entire ionic composition) is not altered significantly. The most potent inhibitor of salt secretion by the gland is bumetanide, $56 \%$ inhibition is already observed at $10^{-5} \mathrm{M}$, at $10^{-4} \mathrm{M}$ the secretion 
stops completely. Another potent inhibitor is piretanide $\left(24 \%\right.$ and $78 \%$ inhibition at $10^{-5}$ and $\left.10^{-4}\right)$, followed by furosemide ( $12 \%$ and $57 \%$ inhibition) and Bay g $2821\left(60 \%\right.$ inhibition at $\left.10^{-4} \mathrm{M}\right)$. For all diuretics the onset of inhibition of the salt secretion in the perfused gland was rapid (inhibition was observed 5 min after start of the perfusion with the diuretic) and the inhibition was rapidly (10 min after perfusion without diuretic) and in most cases completely reversible. This behaviour is exemplified in figure 3 with bumetanide.

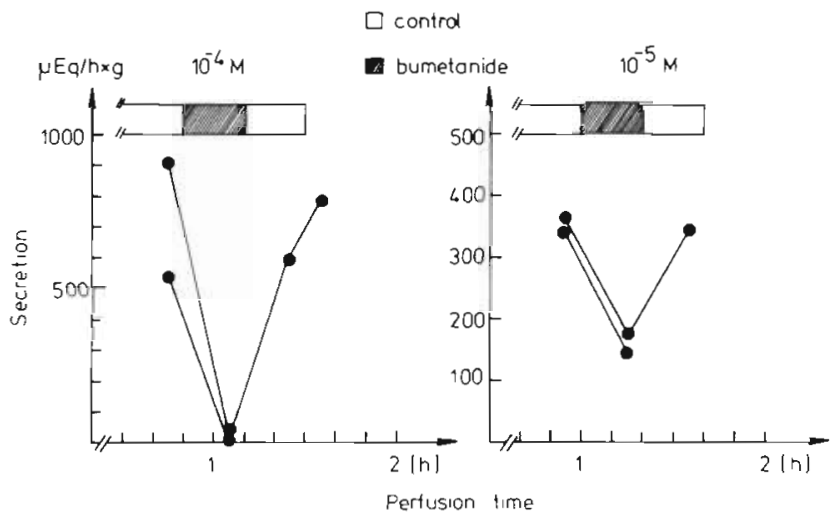

Fig. 3. Scyliorhinus canicula. Onset and reversibility of bumetanide effect on salt secretion by the rectal gland. Hatched bars: period during which gland was perfused with a bumetanide containing solution. Concentrations of the diuretic used are indicated. For further details see legend to Figure 1

\section{DISCUSSION}

The results obtained on the general characteristics of the salt secretion by the rectal gland of Scyliorhinus canicula perfused in situ are quite similar to those published for the rectal gland of Squalus acanthias perfused in vitro (Silva et al., 1977). This holds for the rate of secretion $\left(650 \mu \mathrm{Eq}\right.$ sodium $\mathrm{h}^{-1} \mathrm{~g}^{-1}$ wet weight compared to 900 ) the sodium concentration in the secreted fluid (483 $\mathrm{mEq}$ compared to 419), the sodium dependence of chloride secretion and the inhibition of the secretion by ouabain. Silva et al. (1977) also reported an inhibition of secretion by $10^{-4} \mathrm{M}$ furosemide to an extent identical to the inhibition observed in our studies.

In the present investigation - after having established the above mentioned similarities - emphasis was placed on the question, whether other diuretics, known to act on the ascending limb of Henle's loop of mammalian kidneys also inhibit sodium chloride secretion in the isolated perfused rectal gland. Two classes of compounds were investigated: the sulphamoyl diuretics furosemide (Muschaweck and Hajdú, 1964), piretanide (Merkel et al., 1976) and bumetanide (Feit et al.
1972) and a 3-amino-2-pyrazolin-5-one, Bay g 2821 (Loew and Meng, 1977; Möller et al., 1977). Outof the class of sulphamoyl diuretics, bumetanide was the most potent inhibitor of salt secretion; $50 \%$ inhibition was obtained at about $10^{-5} \mathrm{M}$, whereas with furosemide $50 \%$ inhibition was obtained at about $10^{-4} \mathrm{M}$; piretanide had an inhibitory potency between that of furosemide and bumetanide; Bay g 2821 was as effective as furosemide. Thus the sequence of potency for inhibition of shark rectal gland secretion would be bumetanide $>$ piretanide $>$ furosemide $=$ Bay g 2821 .

If one tries to construct the corresponding sequence for the sodium chloride transport in the thick ascending limb of the mammalian kidney, the following picture emerges. In the awake dog bumetanide has a higher diuretic potency than piretanide, whereas in the rat bumetanide has only a low diuretic activity. In dogs as well as rats piretanide is more potent than furosemide (Muschaweck and Hropot, unpublished). Bay g 2821, on the other hand, is more potent than furosemide in dogs but less potent in rats (Loew and Meng, 1977; Möller et al., 1977). These results obtained in the whole animal do not only reflect the sensitivity of the target tissue to the diuretics, but are markedly influenced by pharmacodynamic parameters. The low potency of bumetanide in rat, for example, can be explained by the high rate of metabolic conversion of the drug in this animal and by a higher binding to plasma proteins (Østergaad et al., 1973), both parameters reduce the concentration of free bumetanide in the plasma. In addition, furosemide (and probably also other loop diuretics) are excreted by the proximal tubule (Sörgel et al., 1979); thereby the intratubular concentration of the diuretic is established, that is needed for an inhibition of the salt transport in the ascending limb. In the isolated perfused thick ascending limb of Henle's loop prepared from rabbit or rat kidney medulla bumetanide is about 14 times as potent as furosemide (Imai, 1977).

In another in vitro system, namely in isolated cells derived from rabbit kidney thick ascending limb, the sodium chloride dependent respiration is also more strongly inhibited by bumetanide than by furosemide (Bayerdörffer, Eveloff, R. Kinne, unpublished). Thus for the thick ascending limb of mammalian kidney the following sequence might be postulated: bumetanide $>$ piretanide $>$ furosemide $=$ Bayg 2821, i. e. a sequence identical to the one obtained for the rectal gland of Scyliorhinus canicula.

Thus our data would support the assumption that the basic elements (at least the diuretic sensitive system) involved in active chloride transport of the shark rectal gland and of the thick ascending limb of mammalian kidney might be similar. It has to be pointed out, however, that there are also differences in the salt 
transport processes of the two epithelia. For example, after replacement of sodium by choline or tetramethylammonium in the perfusate of the isolated thick ascending limb the chloride-dependent electrical potential difference across the epithelium remains unchanged and is reduced by bumetanide, a finding that suggests that also sodium independent chloride movements can occur, which are inhibited by diuretics (Burg and Green, 1973; Imai, 1977). Furthermore, the sensitivity of the mammalian system to furosemide and bumetanide is much higher than the sensitivity of the rectal gland (Silva et al., 1977). Therefore further studies, for example with isolated plasma membrane vesicles - as already initiated with the rectal gland (Eveloff et al., 1978) - are necessary in order to prove or disprove the assumption stated above.

Acknowledgements. We thank Dr. Muschaweck (Hoechst Pharmaceuticals, FRG) for providing us with the sodium salts of furosemide and piretanide, Dr. Heinzel (Dr. Karl Thomae $\mathrm{GmbH}$ ) for providing us with bumetanide and Dr. Garthoff (Bayer Pharmaceuticals) for the gift of Bay g 2821. We also would like to express our gratitude to the Section Gastforschung at the Meeresstation Helgoland for their extraordinary willing and friendly support of our work.

\section{LITERATURE CITED}

Burg, M. (1976). Tubular chloride transport and the mode of action of some diuretics. Kidney Int., 9, 189-197.

Burg, M. and Green, N. (1973). Function of the thick ascending limb of Henle. Am. J. Physiol., 224, 653-668.

Eveloff, J., Kinne, R., Kinne-Saffran, E., Murer, H., Silva, P.,
Epstein, F. H., Stoff, J. and Kinter, W. B. (1978). Coupled Sodium and Chloride Transport into Plasma Membrane Vesicles Prepared from Dogfish Rectal Gland. Pflügers Arch. ges. Physiol., 378, 87-92.

Feit, P. W., Tvaermose Nielsen, O. B and Bruun, H. (1972). Structure-Activity Studies on Sulfamyl Diuretics. J. mednl pharm. Chem., 15, 437.

Imai, M. (1977). Effect of bumetanide and furosemide on the thick ascending limb of Henle's loop of rabbits and rats perfused in vitro. Eur. J. Pharmac., 41, 409-416.

Loew, D. and Meng, K. (1977). The renal mechanism of Bay g 2821. Pharmatherapeutica, 1, 6.

Merkel, W. Bormann, D., Mania, D., Muschaweck, R. and Hropot, M. (1976). Piretanide (Hoe 118) a new high ceiling salidiuretic. (Chimica Therapeutica, Sept.-Oct. 11), Eur. J. Med. Chem., 5, 399-406.

Möller, E., Horstmann, H., Meng, K. and Loew, D. (1977). 3-amino-1 (3,4-dichloro- $\alpha$-methyl-benzyl)-2-pyrazolin-5one (Bay g 2821), a potent diuretic from a new substance class. Separatum Experienta, 33, 382.

Muschaweck, R. and Hajdú, P. (1964). Die salidiuretische Wirksamkeit der Chlor-N-(2-furylmethyl)-5-sulfamylanthranilsäure. Arzneimittel-Forsch., 14, 44-47

Østergaard, E. H., Magnussen, M. B., Kaergaard-Nielsen, C., Eilersten, E. and Frey, H. H. (1972). Pharmacological properties of 3-n-butylaminol-4-phenoxy-5-sulfamyl benzoic acid (Bumetanide), a new potent diuretic. ArzneimittelForsch., 22, 66-72.

Rocha, A. S. and Kokko, J. P. (1973). Sodium Chloride and water transport in the medullary thick ascending limb of Henle. J. clin. Invest, 52, 612-623.

Silva, P., Stoff, J., Field, M. Fine, L., Forrest, J. N. and Epstein, F. H. (1977). Mechanism of active chloride secretion by shark rectal gland: role of Na-K-ATPase in chloride transport. Am. J. Physiol., 233, 298-306.

Sörgel, F, Muschaweck, R. and Hropot, M. (1979). Pharmacokinetics and Pharmacodynamics of Furosemide in the beagle dog. Naunyn-Schmiedebergs Arch. exp. Path. Pharmak. (in press) 